\title{
INFLUÊNCIA DA VARIABILIDADE CLIMÁTICA NA PRODUÇÃO DE LEITE NA REGIÃO SEMIÁRIDA DO NORDESTE DO BRASIL
}

\author{
BARBOSA, Vanessa Vasconcelos - vanessabach2013@gmail.com \\ Universidade Federal do Pernambuco / UFPE
}

SOUZA, Weronica Meira de - weronicameira@gmail.com

Universidade Federal Rural do Pernambuco / UFRPE

\author{
GALVÍNCIO, Josicleda Dominicano - josicleda@hotmail.com \\ Universidade Federal do Pernambuco / UFPE
}
SOBRAL, Maria do Carmo Martins - msobral@ufpe.br
Universidade Federal do Pernambuco / UFPE

\begin{abstract}
RESUMO: A pecuária leiteira é um dos setores produtivos mais sensíveis às variações do clima, e sua atividade representa um importante papel na economia do Agreste Central, Meridional e Setentrional de Pernambuco (região semiárida), sobretudo na sustentabilidade das propriedades rurais de base familiar. Este trabalho objetiva analisar o impacto da variabilidade climática na produção de leite em escala temporal no Agreste pernambucano e determinar um modelo que represente a influência da variabilidade da precipitação pluviométrica na produção leiteira. Foram utilizados dados diários de precipitação pluviométrica de 21 estações no período de 1960 a 2014 distribuídos na região, cedidos pela Agência Pernambucana de Águas e Clima - APAC, e dados anuais de produção de leite de 1974 a 2014 do IBGE. Utilizou-se o aplicativo Climap 3.0 e o software Statistical Package for Social Sience (SPSS) para processamento dos dados. As análises das tendências climáticas da precipitação indicaram alta variabilidade do clima e má distribuição das chuvas durante o ano, com tendência de diminuição pluviométrica na região dos índices climáticos. A variável precipitação contribui com $36 \%$ (modelo estatístico) na produção de leite no Agreste pernambucano.
\end{abstract}

PALAVRAS-CHAVE: Precipitação pluviométrica; Tendência climática; Modelo estatístico.

INFLUENCE OF CLIMATE VARIABILITY IN MILK PRODUCTION IN NORTHEAST SEMI-ARID REGION

ABSTRACT: The dairy cattle is one of most sensitive sectors to climate variability, and its activity plays an important role in economy of Agreste Central, Southern and Northern of Pernambuco (semi-arid region), especially in sustainability of family-based rural properties. This work to analyze the impact of climatic variability on milk production on a temporal scale in Agreste region of Pernambuco, and to determine a model that represents influence of rainfall variability on milk production. Was used daily rainfall data from 21 stations from period 1960 to 2014 distributed in the region provided by Pernambuco State Agency for Water and Climate - APAC, and annual data of milk production 1974 to 2014 from IBGE. The software Climap 3.0 and the Statistical Package for Social Sience (SPSS) were used for data processing. The analysis of climatic trends of precipitation indicated high climatic variability and poor distribution of rain during the year, with tendency to decrease rainfall in region of climatic indexes. The rainfall contributes $36 \%$ (statistical model) to the milk production in Agreste Pernambuco.

KEYWORDS Rainfall; Climat trend; Statistical model.

\section{INTRODUÇÃO}

As condições climáticas de uma região são um dos principais componentes do quadro natural, e a partir da investigação do comportamento 
climático de uma região é possível planejar a prática das atividades de forma a otimizar a utilização dos recursos disponíveis e mensurar os impactos das suas variações.

O conhecimento da distribuição espaço-temporal das chuvas de uma região contribui para o gerenciamento das decisões quanto às medidas necessárias para mitigar os danos decorrentes das variabilidades climáticas. A elevada vulnerabilidade a que está exposta o Nordeste brasileiro em decorrência das oscilações climáticas gera um quadro de destruição de plantações, desemprego e fome (LIMA et al., 2018). O Agreste pernambucano consiste numa área de evidente vulnerabilidade devido à relação entre os fatores de produção e os fatores climáticos, baixa infraestrutura viária, insuficiência de equipamentos urbanos e serviços básicos e quase nula preparação da população para lidar com situações climáticas extremas.

Conforme Galvíncio e Moura (2005), o problema comum de secas na região Nordeste do Brasil está mais relacionado com a distribuição irregular de chuvas do que propriamente com a falta das mesmas. Outros fatores, tais como a baixa capacidade de retenção de umidade no solo e altas taxas de evaporação e evapotranspiração contribuem para agravar o problema (ASSIS, SOUZA E SOBRAL, 2015). Estudo recente realizado por Pereira et al. (2017) no Agreste Central de Pernambuco identificaram mudança no padrão da precipitação total anual de 1963 a 2013 por meio do índice de anomalia de chuva, com aumento da frequência de anos chuvosos até o final da década de 80 e redução das chuvas a partir da década de 90 , cujos anos secos passaram a predominar na região.

Cabe salientar os reais desafios impostos pelas condições climáticas da região semiárida e suas influências na produção do leite, conforme informações da Empresa Brasileira de Pesquisa Agropecuária - EMBRAPA (2010), que indica a pecuária leiteira como um dos setores mais sensíveis às variações do clima, corroborada por Pires, Teodoro e Campos (2000), quando comentam que nesta região as altas temperaturas do ar, associadas com intensa radiação solar, impõe carga adicional de calor nos animais a pasto, ocasionando estresse calórico e queda na produção.

A cadeia produtiva do leite possui grande expressividade socioeconômica para o Nordeste brasileiro, sendo uma das atividades mais presentes na região semiárida, juntamente com a agricultura. Conforme Monteiro (2007), em Pernambuco, cerca de 14 mil pequenos e médios produtores estão na atividade leiteira, concentrados principalmente na região Agreste, e geram uma produção diária de 980 mil litros. Porém, o baixo nível tecnológico aplicado na exploração leiteira e a falta de gestão mais profissionalizada nas propriedades conferem ao segmento produtivo indicadores técnicos aquém das suas reais potencialidades (SEBRAE, 2013).

Uma característica marcante dessa atividade leiteira é a existência de pequenas e médias propriedades com características de agricultura familiar, onde comumente essa atividade é basilar na geração de renda, muitas vezes fazendo parte de um contexto histórico de tradição transmitida através das gerações. Nesse ínterim, "(...) a falta de informação, assistência e investimentos na produção leiteira geram baixa produtividade e menor qualidade do produto (MONTEIRO, 2007)." Sabendo-se do importante papel que a atividade leiteira desempenha na sustentabilidade das propriedades rurais de base familiar na 
região Agreste de Pernambuco, uma vez que mesmo não sendo responsáveis por parte substancial da produção global, insere boa parte da população num contexto de geração de renda, é importante que se busque equidade social no desenvolvimento dessa atividade, proporcionando condições seguras de produção de leite nas variadas escalas de produção.

$\mathrm{Na}$ região semiárida, de forma geral, onde as singulares condições climáticas representam uma limitação à prática de algumas atividades, somente o planejamento baseado em estudos dessa natureza pode aperfeiçoar o desenvolvimento de setores como o da pecuária leiteira, de forma a garantir a sustentabilidade das propriedades rurais de base familiar. Assim, esse estudo objetiva analisar o impacto da variabilidade climática na produção de leite em escala temporal no Agreste pernambucano e determinar um modelo que represente a influência da variabilidade da precipitação pluviométrica na produção leiteira do Agreste pernambucano, verificando inicialmente as tendências climáticas da precipitação pluviométrica na região estudada a partir dos dados observados, avaliando a evolução temporal da precipitação pluviométrica e da produção de leite nas regiões do Agreste Meridional, Central e Setentrional e representando estatisticamente essa influência.

\section{MATERIAL E MÉTODOS}

\subsection{OBTENÇÃO E ANÁLISE DE DADOS}

Foram obtidos dados diários de precipitação pluviométrica registrados em 21 estações pluviométricas, por meio do banco de dados da Agência Pernambucana de Águas e Clima (APAC) e do Instituto de Tecnologia de Pernambuco (ITEP), referentes aos municípios componentes do Agreste Setentrional, Meridional e Central de Pernambuco no período de 1960 a 2014, cuja distribuição das estações pode ser observada na Figura 1. Foi realizada uma análise de consistência das séries através do diagnóstico da qualidade dos dados pluviométricos brutos e verificação da homogeneidade dos mesmos em relação ao padrão regional. 


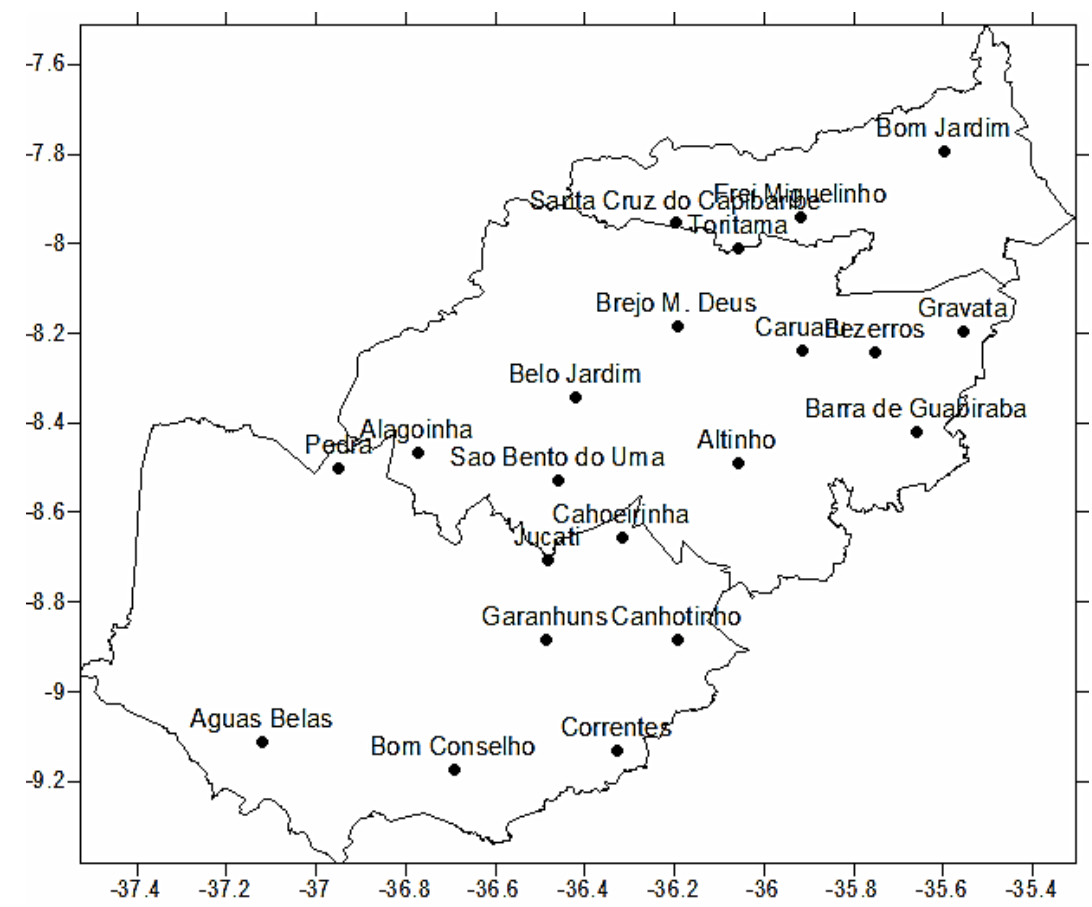

Figura 1 - Localização das estações pluviométricas do Agreste Central, Meridional e Setentrional de Pernambucano.

Através da interpretação dessas informações e com o auxílio do aplicativo Climap 3.0, foi possível caracterizar o regime histórico de precipitação para o Agreste pernambucano, indicando a variabilidade climática.

Os dados referentes à produção de leite foram adquiridos através do Instituto Brasileiro de Geografia e Estatística (IBGE), para cada município do Agreste pernambucano em que foram conseguidos dados de precipitação utilizáveis. Tais dados apresentam-se unicamente referentes ao leite de vaca, produzido anualmente por cada município, em mil litros, do período de 1974 a 2014, não existindo registros oficiais de produção de leite no período anterior ao ano de 1974.

Utilizou-se o Statistical Package for Social Science for Windows (SPSS), software livre, para determinar o modelo que tenha um melhor ajuste para as variáveis precipitação e produção do leite. O SPSS é um software para análise estatística de dados, em um ambiente amigável, utilizando-se de menus e janelas de diálogo, que permite realizar cálculos complexos e visualizar seus resultados de forma simples e autoexplicativa.

\subsection{PROCEDIMENTOS METODOLÓGICOS}

\section{TENDÊNCIAS CLIMÁTICAS DA PRECIPITAÇÃO PLUVIOMÉTRICA}

As tendências climáticas da precipitação pluviométrica na região estudada foram analisadas através do aplicativo Climap 3.0, com interface gráfica, que auxilia a análise das séries de dados meteorológicos de chuva e de temperatura do ar, com a associação de informações e criação de gráficos 
(SALVADOR, 2017). Neste trabalho foram utilizadas apenas as informações da precipitação pluviométrica, referentes ao período de 1960 a 2014, sendo geradas séries mensais, trimestrais e anuais para os seguintes índices:

i.Totais mensais, trimestrais e anuais da precipitação pluviométrica;

ii.DPP: Desvio padronizado da precipitação dos totais mensais, trimestrais e anuais. DPP = (total-média) / desvio-padrão;

iii.Pr1: Número de dias por ano com chuvas significativas ( $\geq 1 \mathrm{~mm} / \mathrm{dia}$ );

iv.Pr10: Número de dias por ano com precipitação $\geq 10 \mathrm{~mm}$;

v.Pr20: Número de dias por ano com precipitação $\geq 20 \mathrm{~mm}$;

vi.Pr50: Número de dias por ano com precipitação $\geq 50 \mathrm{~mm}$;

vii.Per95p: Número de dias com precipitação $\geq$ ao percentil 95 das chuvas significativas (ocorrência/ano);

viii.Per99p: Número de dias com precipitação $\geq$ ao percentil 99 das chuvas significativas (ocorrência/ano);

ix.Prmax1d: Maior precipitação ocorrida em um dia por ano (mm).

\section{IMPACTOS DA VARIABILIDADE CLIMÁTICA NA PRODUÇÃO DE LEITE}

Para identificar o impacto da variabilidade climática na produção de leite em escala temporal no Agreste pernambucano foi realizado o levantamento de dados de produção de leite através do IBGE para os municípios da região Agreste Central, Meridional e Setentrional no período de 1974 a 2014. Também foram identificadas as estações pluviométricas com totais anuais no mesmo período existentes nas três regiões do Agreste, avaliando a distribuição espacial dos dados históricos.

Após devidamente arquivados num banco de dados e agrupados por microrregião, foi realizada e média aritmética por região através do Excel e gerados gráficos que permitem a visualização da produção dos municípios selecionados em relação à média da microrregião, evidenciando os municípios que possuem maior expressividade nessa atividade.

Para representar estatisticamente a influência da variabilidade da precipitação pluviométrica na produção leiteira no Agreste pernambucano, foi utilizado o Statistical Package for Social Science for Windows - SPSS, software de apoio à tomada de decisão que inclui aplicação analítica, Data Mining, Text Mining e estatística que transformam os dados em informações. Com o software SPSS, determinou-se o modelo que mais se ajusta às variáveis estudadas.

Assim sendo, para saber como estão associadas às variáveis, foi elaborado um gráfico com informações observadas no período de 1974 a 2014 da precipitação pluviométrica e da produção do leite no Agreste de pernambucano, a partir da média aritmética dos dados observados nas regiões do Agreste Meridional, Central e Setentrional. 


\section{RESULTADOS E DISCUSSÃO}

\subsection{ANÁlise dAS tendênCIAS Climáticas dA PRECIPITAÇÃo PLUVIOMÉTRICA \\ MÉDIAS HISTÓRICAS MENSAIS E TRIMESTRAIS}

A partir da verificação das séries pluviométricas mais consistentes encontradas entre os municípios componentes das três microrregiões do Agreste de Pernambuco, constatou-se que apenas nos municípios de São Bento do Una e Caruaru, no Agreste Central, e também Garanhuns, Bom Conselho, Pedra e Jucati, no Agreste Meridional, foi possível gerar os gráficos mensais e trimestrais da precipitação pluviométrica.

Analisando uma série de 54 anos (entre 1960 e 2014), verificou-se que o comportamento histórico da precipitação nos municípios supracitados demonstra, de forma geral, a concentração do período chuvoso nos dois primeiros trimestres do ano, com maior expressividade entre os meses de março a julho, apresentando de outubro a novembro os menores índices de precipitação.

Dentre as características do regime climático dessa área, a mais evidente é a definição de uma estação seca e outra chuvosa, sendo a chuvosa mais concentrada, e a seca, predominante ao longo do ano. Apesar de existirem vários tipos climáticos dentro da região agreste, essas condições revelam de forma geral o comportamento da precipitação na região Agreste do Estado de Pernambuco.

Tais condições revelam a má distribuição da precipitação ao longo do ano, evidenciando a concentração desta em um período relativamente curto, enquanto em grande parte do ano ocorre um evidente déficit hídrico (Figura 2). Esse comportamento climático corresponde ao regime predominante nos climas tropical quente e seco (semiárido) e tropical quente sub-úmido seco, predominantes entre os referidos municípios. 

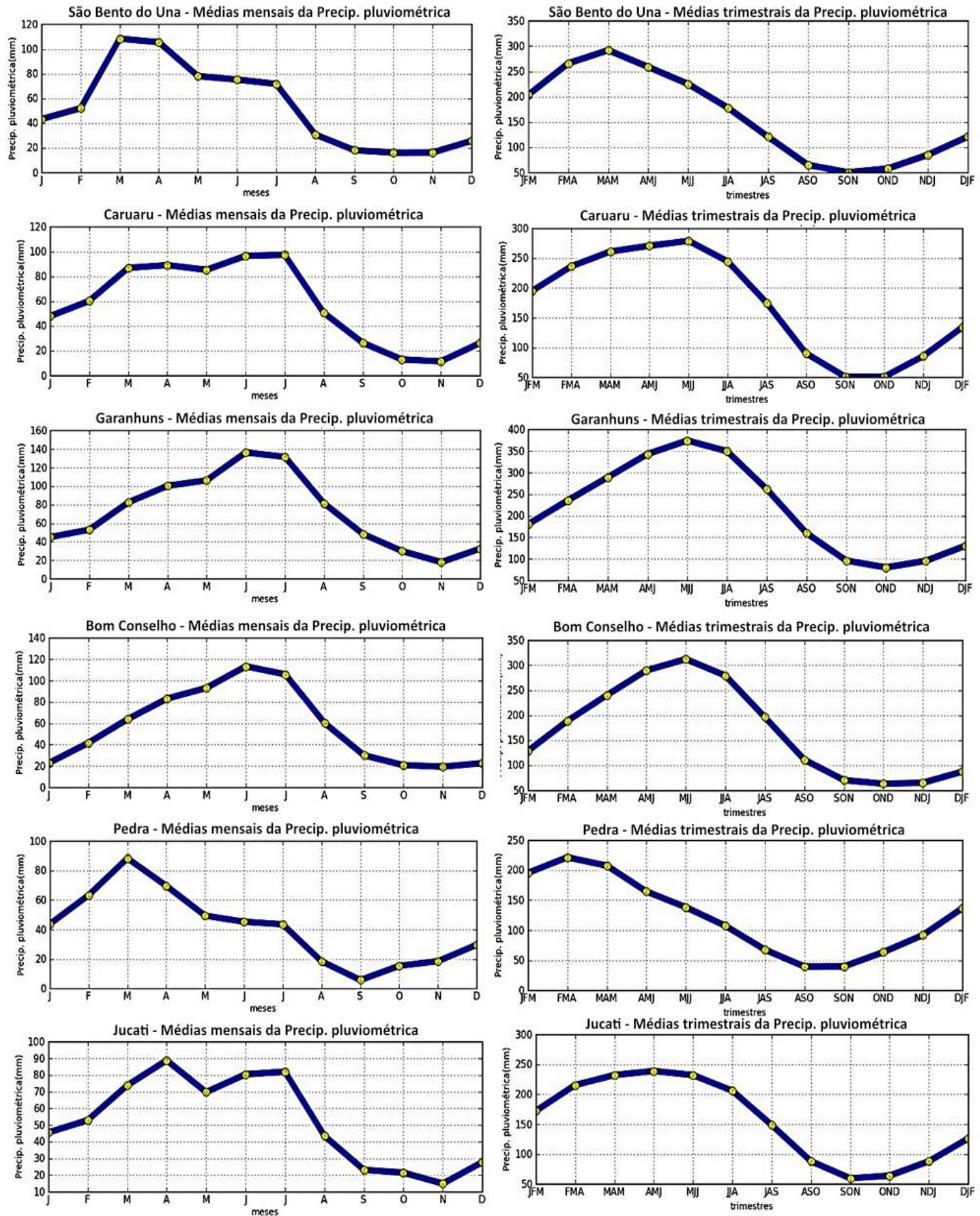

Figura 2 - Médias históricas mensais e trimestrais da precipitação pluviométrica dos municípios de São Bento do Una, Caruaru, Garanhuns, Bom Conselho, Pedra e Jucati. 
Ponderando que na região Agreste a concentração de chuvas em um curto período de tempo atrelada à baixa capacidade do solo de retenção de água possa acarretar outros problemas ambientais, como levar ao escoamento superficial e erosão, enfraquecimento do solo e redução da produção, deve-se conjecturar que os investimentos ligados ao desenvolvimento do setor nessa área atentem para a busca de maior eficiência na captação e gestão da água precipitada ao longo do ano, otimizando seu uso enquanto recurso e evitando perdas econômicas e socioambientais.

\section{TENDÊNCIAS CLIMÁtICAS DA PRECIPITAÇÃO PLUVIOMÉTRICA A PARTIR DO DESVIO PADRONIZADO}

Na área de estudo, apenas os municípios de Caruaru no Agreste Central, Bom Conselho, Garanhuns e Pedra no Agreste Meridional apresentaram índices significativos de precipitação total e desvio padronizado em virtude principalmente da qualidade dos dados obtidos. É possível associar que além da má distribuição das chuvas já detectada existe grande irregularidade interanual desta variável, expressa nos valores totais (colunas azuis com linhas de média) e nos desvios padronizados positivos (em azul) e negativos (em vermelho).

As séries evidenciam ampla variabilidade anual no volume total de precipitação, demonstrando grande oscilação entre os índices, com a ocorrência de anos extremamente secos e outros chuvosos. A diversidade retratada, por sua vez, apresenta semelhanças entre os municípios diante da existência e intensidade de eventos extremos, alertando que tais ocorrências impactam de forma significativa toda a região Agreste. Tais episódios são evidentes nos desvios padronizados negativos nos anos de 1967, 1970, 1993 e 2012 e positivos em 1977 e 2010 nos quatro municípios (Figura 3), embora na precipitação total anual não seja visível. 

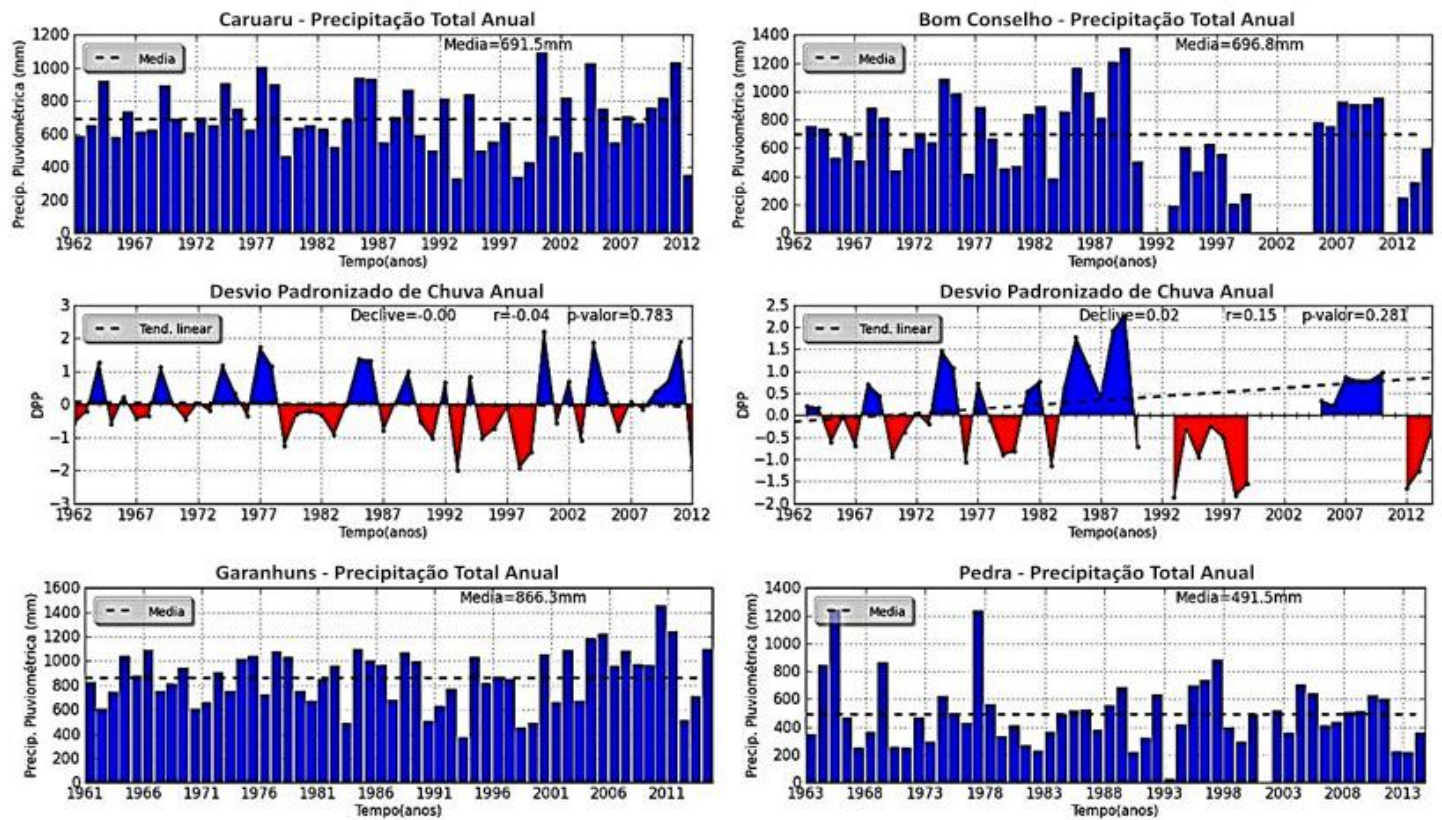

Desvio Padronizado de Chuva Anual
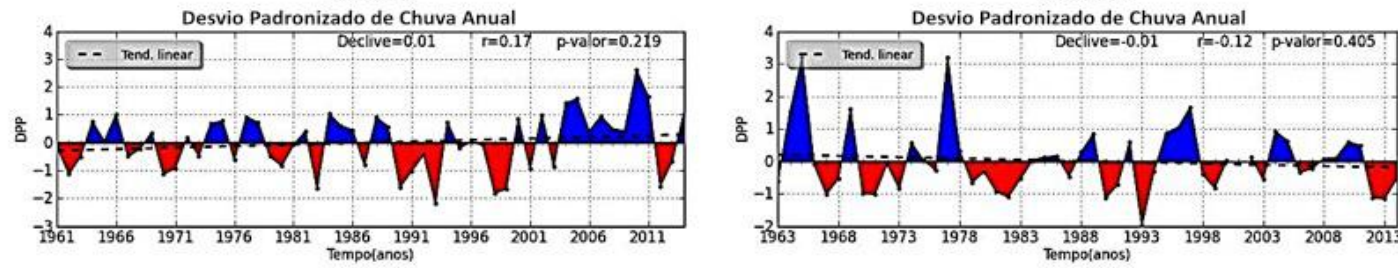

Figura 3 - Totais anuais de precipitação pluviométrica e desvio padronizado dos municípios de Caruaru, Bom Conselho, Garanhuns e Pedra.

As médias anuais da precipitação no Agreste se apresentam muito baixas, variando de 490 a $866 \mathrm{~mm}$, e considerando que assim como nos valores totais existem alterações importantes em torno da média anual, o desvio padronizado DPP demonstra as probabilidades dos valores se distanciarem da média, positivamente ou negativamente. Foram evidenciadas ocorrências positivas e negativas de DPP, tornando ainda mais expressiva a variabilidade climática na área de estudo.

Destacam-se na avaliação deste item os desvios negativos ocorridos em Caruaru nos anos de 1993 e 1998, em Bom Conselho entre 1992 e 1997, em Garanhuns e Pedra em 1990 e 1993. Entre os valores positivos de DPP, podemse citar em Caruaru os anos de 2000, 2003 e 2010, em Bom Conselho de 1984 a 1988, em Garanhuns de 2004 a 2011 e em Pedra, os anos de 1964 e 1977 e 1995.

As médias anuais observadas na Figura 3 atentam para ocorrência de baixos índices de precipitação em toda a região, situação que se agrava ainda mais nos episódios de anos extremos secos. Considerando o uso e ocupação do solo na região, predominantemente rural, bem como as atividades desenvolvidas ligadas à agricultura e pecuária, tal constatação reforça as 
condições naturais da região Agreste como desafiadoras em níveis de precipitação.

Comparativamente a este estudo, Medeiros et al. (2015), que avaliou uma série de dados de precipitação diária de um período semelhante (1961 a 2012) numa análise quantitativa da variabilidade de chuvas em João Pessoa PB, identificou médias anuais que variam em torno de 972 a $3800 \mathrm{~mm}$ para a referida localidade. Nesse caso, a alta variabilidade anual da precipitação expressa em um contexto regional distinto, com elevados índices de precipitação pluviométrica, numa área predominantemente urbana, anuncia como a gravidade dos impactos associados aos eventos extremos climáticos podem também variar de acordo com as características de cada ambiente e de cada regime de precipitação.

Não foram identificadas tendências de precipitação negativas ou positivas significativas nesta análise, exceto no município de Bom Conselho, que pode ter apresentado esta alteração em virtude da ausência de dados em parte da série avaliada. A não existência de tendências de precipitação no Agreste, por sua vez, não figura elemento de grande expressividade no contexto climático da área de estudo, visto que a variabilidade anual encontrada por si só já representa uma característica relevante.

A influência da variável precipitação, além de associada a riscos ambientais já pressupostos nesta análise, pode ainda ser atrelada a ocorrências de incêndios, conforme identificam estudos realizados por Pezzopane, Neto e Vilela (2011) no município de Viçosa - MG. Baseados em dados de precipitação diária do período de 1968 a 1996, buscaram detectar locais de maior risco de incêndios considerando que são estes muitas vezes responsáveis pela perturbação de ecossistemas naturais e perdas nos setores agrícola e florestal. Os autores comentam ainda que as preocupações com estas ocorrências são constantes nos meses de inverno e primavera, devido, principalmente, aos baixos índices pluviométricos.

O conhecimento do comportamento histórico da precipitação anual é uma das etapas mais fundamentais na redução do risco climático associado a setores produtivos como o leiteiro, uma vez que a variabilidade temporal traz significativas informações acerca de possíveis periodicidades, tendências ou descontinuidades climáticas, fornecendo suporte em estudos direcionados ao desenvolvimento da capacidade adaptativa da região Agreste por meio das forçantes moduladoras das qualidades meteorológicas.

\section{TENDÊNCIAS CLIMÁTICAS A PARTIR DOS ÍNDICES EXTREMOS DE PRECIPITAÇÃO}

Como forma de expor a ocorrência de níveis extremos de precipitação, foram selecionados os valores representativos do número de dias por ano com chuvas significativas $\geq 1 \mathrm{~mm}, \geq 10 \mathrm{~mm}, \geq 20 \mathrm{~mm}, \geq 50 \mathrm{~mm} /$ dia e número de dias com precipitação $\geq$ ao percentil 95 das chuvas expressivas (Tabela 1), e partir destes, as tendências de aumento ou diminuição de sua ocorrência foram identificados nas três microrregiões do Agreste pernambucano, distribuídas espacialmente entre os Agrestes Setentrional, Central e Meridional, apenas nos locais em que o diagnóstico apresentou significância estatística. 
Tabela 1 - Valores encontrados para os índices extremos climáticos (Pr1, $\operatorname{Pr} 10, \operatorname{Pr} 20$, Pr50 e Per95p) através do Climap 3.0. Os índices marcados em negrito apresentam significância estatística ( $* p<0,05$ : alta significância estatística; $* * p<0,1$ : boa significância estatística)

\begin{tabular}{|c|c|c|c|c|c|c|}
\hline RD & Municipio & Prl & Prl0 & Pr20 & Prnn50 & Pr95 \\
\hline \multirow{4}{*}{ 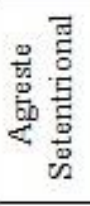 } & Bom Jardim & $-0,75^{*}$ & $-0,27$ * & $-0,08$ & 0,00 & $-0,01$ \\
\hline & Frei Miguelinho & $-0,14$ & $-0,06$ & $0,01 * *$ & $-0,01$ & $-0,01$ \\
\hline & Santa Cruz do Capibaribe & 0,27 & $-0,23 * *$ & $-0,11$ & $-0,01$ & $-0,03$ \\
\hline & Toritama & 0,21 & $-0,07$ & $-0,06$ & $-0,02$ & $-0,01$ \\
\hline \multirow{10}{*}{ 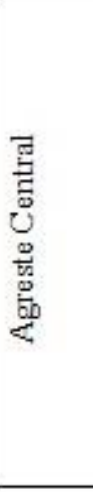 } & Alagoinha & $-0,06^{* *}$ & $-0,04$ & $-0,04$ & $-0,01$ & $-0,03$ \\
\hline & Altinho & 0,17 & $-0,13$ & $-0,10^{* *}$ & $-0,01$ & $-0,04$ \\
\hline & Barra de Guabiraba & $-0,06$ & $-0,74^{* *}$ & $-0,49 * *$ & $-0,09$ * & $-0,12$ * \\
\hline & Belo Jardim & $-0,27$ & $-0,15$ & $-0,03$ & $-0,01$ & $-0,02$ \\
\hline & Bezerros & $-0,63$ * & $-0,23 *$ & $-0,05$ & $-0,01$ & $-0,03$ \\
\hline & Brejo da Madre de Deus & $-0,14$ & $-0,22$ ** & $-0,09 *$ & 0,02 & 0,01 \\
\hline & Cachoeirinha & 0,50 * & $-0,11$ ** & $-0,02$ ** & 0,00 & $-0,01$ \\
\hline & Caruaru & 0,19 & $-0,09$ & 0,00 & 0,00 & 0,00 \\
\hline & Gravatá & 0,09 & 0,05 & 0,02 & 0,00 & 0,01 \\
\hline & São Bento do Una & $-1,03$ ** & $-0,32 * *$ & $-0,15 * *$ & $-0,02$ & $-0,04$ \\
\hline \multirow{7}{*}{ 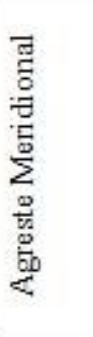 } & Àguas Belas & $-0,70^{*}$ & $-0,19 *$ & $-0,08^{* *}$ & $-0,01$ & $-0,04$ \\
\hline & Bom Conselho & $-0,16$ & $-0,20$ & $-0,08$ ** & 0,00 & $-0,03$ \\
\hline & Canhotinho & $-0,04$ & $-0,09$ & $-0,02$ & 0,01 & 0,03 \\
\hline & Correntes & 0,34 & $-0,02$ & $-0,06$ & $-0,01$ & $-0,01$ \\
\hline & Garanhuns & 0,16 & 0,08 & 0,02 & 0,00 & 0,03 \\
\hline & Jucati & 0,55 & $-0,26$ & $-0,11$ & $-0,02$ & $-0,03$ \\
\hline & Pedra & 0,00 & $-0,08$ & $-0,05$ & $-0,01$ & $-0,01$ \\
\hline
\end{tabular}

A Tabela 1 expõe os valores encontrados para cada índice supracitado atrelado aos municípios que compõem a área de estudo, retratados nos mapas a partir das coordenadas geográficas dos postos de coleta. Por meio desses resultados, é possível perceber que não há total uniformidade no que alude às tendências desses índices entre as localidades, no entanto, existe uma predominância de tendências negativas para a maioria dos índices.

Os resultados obtidos através do Climap 3.0 reunidos na Figura 4 demonstram que no Agreste Setentrional, apenas os índices Pr1, Pr10 e Pr20 obtiveram resultados significativos, todos com tendência à diminuição de sua ocorrência, enquanto no Agreste Central todos os índices apresentaram resultados expressivos, predominantemente com tendência à diminuição, exceto pelo $\operatorname{Pr} 1$, que apresenta tendências positivas em dois postos. O Agreste Meridional, por sua vez, expressou disposições de diminuição de todos os índices registrados, excetuando-se o Pr50, que não apresentou significância estatística em nenhum posto dessa microrregião. 

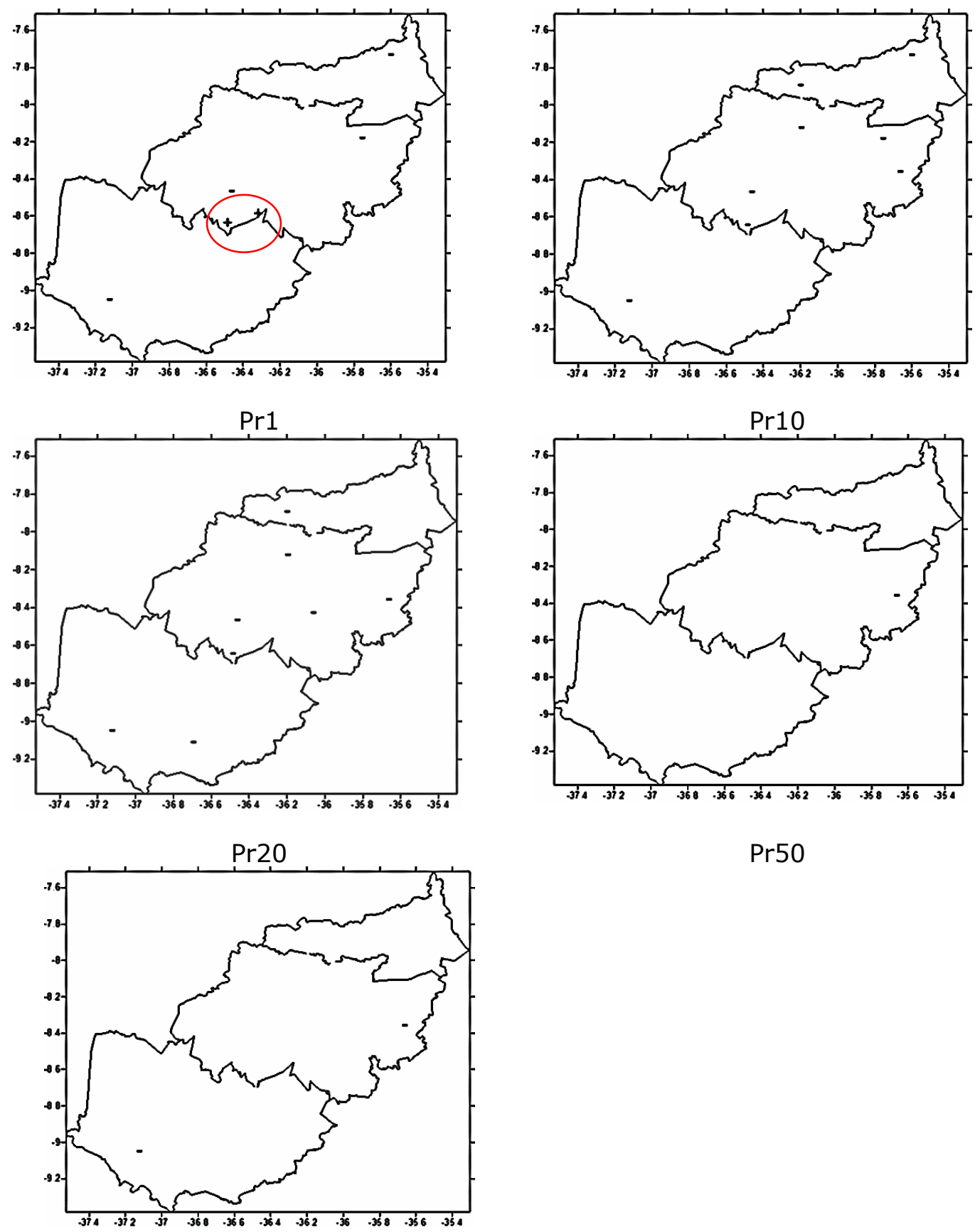

$\operatorname{Pr} 50$

P95

Figura 4 - Distribuição espacial das tendências (- tendência de diminuição e + tendência de aumento) dos índices extremos da precipitação pluviométrica.

O indicativo de baixa ocorrência de eventos extremos na área de estudo, bem como as tendências de diminuição constatadas interpreta-se de forma positiva para a região Agreste, considerando o elevado grau de vulnerabilidade que essa região apresenta às adversidades do clima. No entanto, os riscos ocasionados pela própria variabilidade natural da precipitação não se incluem 
nessa consideração e representam ainda grande risco socioambiental diante do não investimento em enfrentamento a estas questões.

Cabe salientar que, sobretudo nos índices Pr50 e Per95p, houveram pouquíssimos postos que demonstraram significância estatística, portanto, não é possível afirmar tendências seguras que correspondam a todos os municípios da área de estudo. Considerando que esses índices advertem a ocorrência de eventos extremos que revelariam níveis de precipitação intensa, seria desejável que a consistência dos dados favorecesse uma avaliação mais clara e consistente a fim de prevenir tais ocorrências.

A metodologia empregada para a obtenção dos resultados dessa pesquisa é a mesma empregada por Salvador (2014), para analisar índices extremos de precipitação para a região definida como MATOPIBA, que compreende uma nova fronteira agrícola no Brasil, ocupando parte dos Estados do Maranhão, Tocantins, Piauí e Bahia, utilizando o Climap 1.1. Da mesma forma, como resultado, foram identificadas em sua maioria tendências negativas dos extremos da precipitação, sugerindo possível diminuição gradativa da ocorrência desse tipo de evento.

Similarmente, Santos, Melo e Brito (2016), por sua vez, procuraram analisar tendências de índices extremos climáticos para o Estado do Amazonas utilizando dados diários de precipitação do período de 1970 a 2010, para os mesmos índices, utilizando um recurso distinto (RClimdex), obtendo resultados variados para cada item. De forma geral, os autores comentaram que poucos postos apresentaram significância estatística, sendo a ausência de um banco de dados climáticos de longo prazo, um pontual obstáculo à quantificação dos eventos extremos de forma satisfatória.

\subsection{IMPACTOS DA VARIABILIDADE CLIMÁTICA NA PRODUÇÃO DE LEITE EM ESCALA TEMPORAL}

\section{DISTRIBUIÇÃO TEMPORAL DA PRODUÇÃO DE LEITE}

A Figura 5 demonstra como está distribuída a produção de leite entre as microrregiões do Agreste pernambucano no período de 1974 a 2014. O Agreste Meridional (em azul) possui grande destaque, produzindo temporalmente muito acima da média (linha tracejada) da região. O Agreste Central (verde) é o segundo maior produtor da área de estudo, enquanto o terceiro e menos representativo é o Agreste Setentrional (em vermelho). Ao longo do período supracitado, ocorreram variações graduais da produção de leite nas três microrregiões, tal como se apresenta o comportamento da precipitação pluviométrica para o mesmo período, não considerando inicialmente a existência de uma correlação direta entre essas variáveis. Só mais recentemente houve uma elevação significativa dessa produção (Figura 5). 


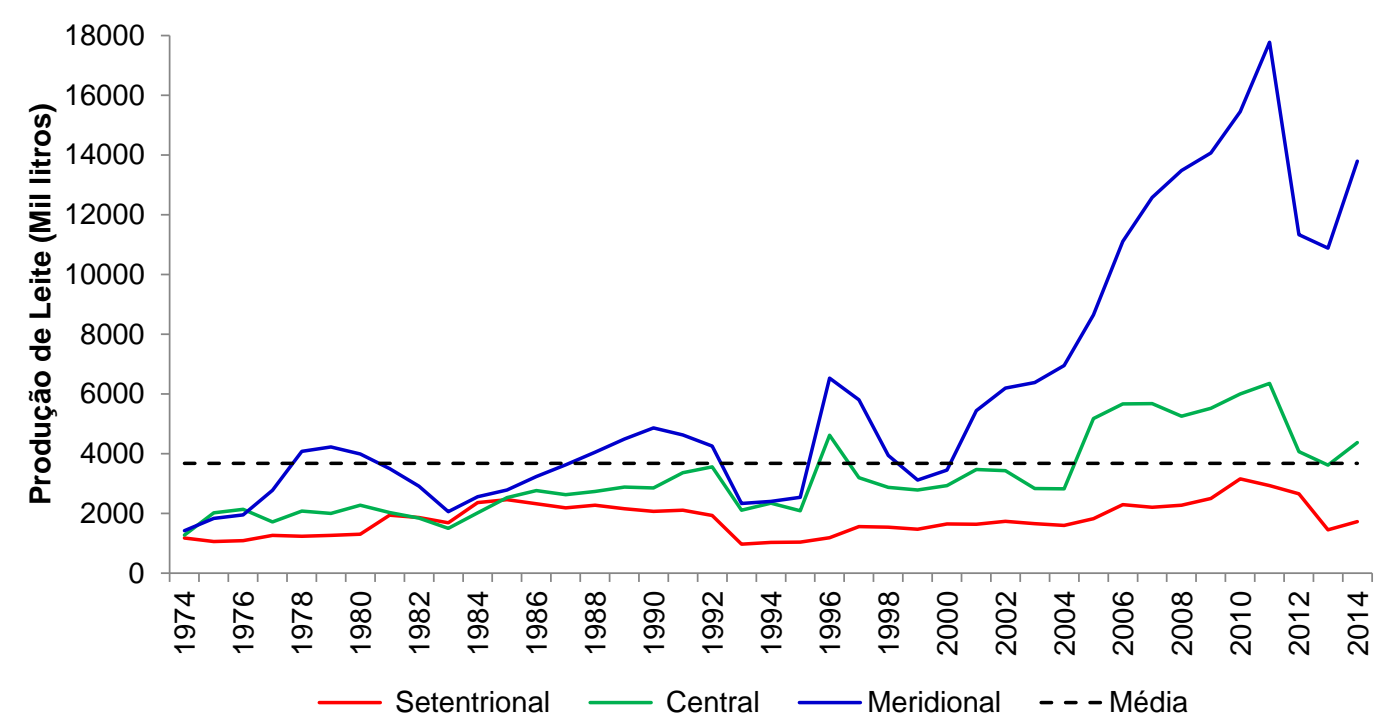

Figura 5 - Distribuição temporal da produção de leite nas regiões do Agreste Setentrional, Central e Meridional e a média da região no período de 1974 a 2014

De forma geral, houve um evidente crescimento da produção ao longo do período estudado, que se deu principalmente em virtude de diversos investimentos realizados no setor. Conforme Correia (2012), no período de 1990 a 1998 ocorreram tentativas de soerguimento das ações na retomada da pecuária leiteira bovina no Nordeste, que se encontrava então em declínio, inclusive com o incremento do Fundo de Desenvolvimento do Nordeste (FNE). Os autores comentam ainda que, com o incentivo às micro e pequenas empresas de Pernambuco lançados partir dos anos 2000, posterior à privatização da Companhia de Industrialização de Leite de Pernambuco (CILPE) e ao surto de febre aftosa, produziram-se novas expectativas de crescimento e desenvolvimento da pecuária leiteira.

Tais informações corroboram com os resultados expostos na Figura 5, que demonstram a partir do ano 2000 um crescimento diferenciado da produção de leite, especialmente no Agreste Meridional, que em 2010 chega a produzir 18000 litros, estabelecendo-se muito acima da média de produção da região, que se expressa em torno de $4000 \mathrm{~L}$.

Outra ação que pode ter potencializado o crescimento da produção de leite no Agreste Meridional mais recentemente foi a instalação do complexo agroindustrial da Perdigão-Batavo (atual Parmalat-Lactalis) no município de Bom Conselho, que anunciado em 2007, conforme exposto pela CONDEPE/FIDEM (2016), previram inicialmente investimentos da ordem dos 130 milhões, contando com o aporte dos recursos do Fundo Constitucional do Nordeste (FCN) e com o incentivo do Governo de Pernambuco, por meio do Programa de Desenvolvimento de Pernambuco (PRODEPE). Este empreendimento possui uma demanda de $150 \mathrm{mil} \mathrm{L/dia,} \mathrm{enquanto} \mathrm{a} \mathrm{empresa} \mathrm{Betânia,} \mathrm{instalada} \mathrm{em}$ Garanhuns, demanda cerca de 100 mil L/dia.

Considerando que a bacia leiteira de Pernambuco é a segunda maior do Nordeste, atrás apenas da Bahia, cabe pontuar que a concentração produtiva desse leite se dá na região Agreste, segundo Correia (2012), por fatores históricos, culturais, climáticos e geográficos. Sendo esta atividade uma das 
alavancas econômicas para o estado, vale salientar que o Agreste Meridional, historicamente, produziu muito mais leite que as outras microrregiões, e que sua tendência de crescimento da produção nos últimos anos conduz a uma representatividade diferencial no setor em nível regional.

Estudos sobre a competitividade da cadeia produtiva de leite em Pernambuco realizados pela EMBRAPA (2009) analisaram que as participações das regiões Agreste Meridional, Central e Setentrional na produção total de leite do Agreste foram de 48\%, 39\% e 14\% em 1995 e de $65 \%$, 27\% e $8 \%$ em 2007, respectivamente. Relacionando tais informações à Figura 5, confirma-se que entre 1995 e 2007, somente a região Agreste Meridional aumentou sua participação no volume total da produção da região Agreste, significando um incremento de 259,5 milhões de litros de leite, em valores absolutos.

É preciso ainda atrelar as informações expostas no gráfico da Figura 5 aos resultados encontrados por Correia (2012), que justificam o aumento substancial da produção de leite ocorrido principalmente no Agreste Meridional a partir de 2005, que se dá em virtude do surgimento do novo cenário do leite em Pernambuco, com a instalação de pequenas e médias empresas de derivados do leite e com a fortificação dos sindicatos (SINDILEITE) em 2006 e da instalação de empresas de grande expressividade já mencionadas.

Conforme identificado pela EMBRAPA (2009), o crescimento da produção de leite de 1995 a 2007 nos Agrestes Meridional e Central ocorreram mais em função do crescimento numérico do rebanho do que de ganhos de produtividade, contrastando com o Agreste Setentrional, cujo aumento da produção ocorreu basicamente devido ao crescimento da produtividade, com adoção de novas tecnologias no processo de produção leiteira.

Embora o aumento da produção tenha sido significativo em todo o Agreste, ainda que por motivos distintos, o Agreste Meridional, por receber incentivos específicos advindos da instalação de novas companhias de grande porte, obteve maior destaque na produção da região a partir de então, concentrando grande parte dos investimentos realizados no setor.

\section{DISTRIBUIÇÃO TEMPORAL DA PRECIPITAÇÃO}

Na Figura 6 se expõe a distribuição temporal da precipitação pluviométrica para o mesmo período, nas três microrregiões do Agreste pernambucano. Assim como demonstram as figuras 2 e 3, a variabilidade climática é evidente, e segue o mesmo comportamento nos Agrestes Meridional, Central e Setentrional. A média anual da região está em torno de $700 \mathrm{~mm}$, e existem algumas diferenças substanciais em volume de precipitação entre as microrregiões, visto que os Agrestes Setentrional e Meridional apresentam um volume de precipitação maior, implicando em mais anos com chuvas acima da média da região, enquanto o Agreste Central encontra-se abaixo das médias regionais, ultrapassando-a apenas em anos atípicos (Figura 6). 


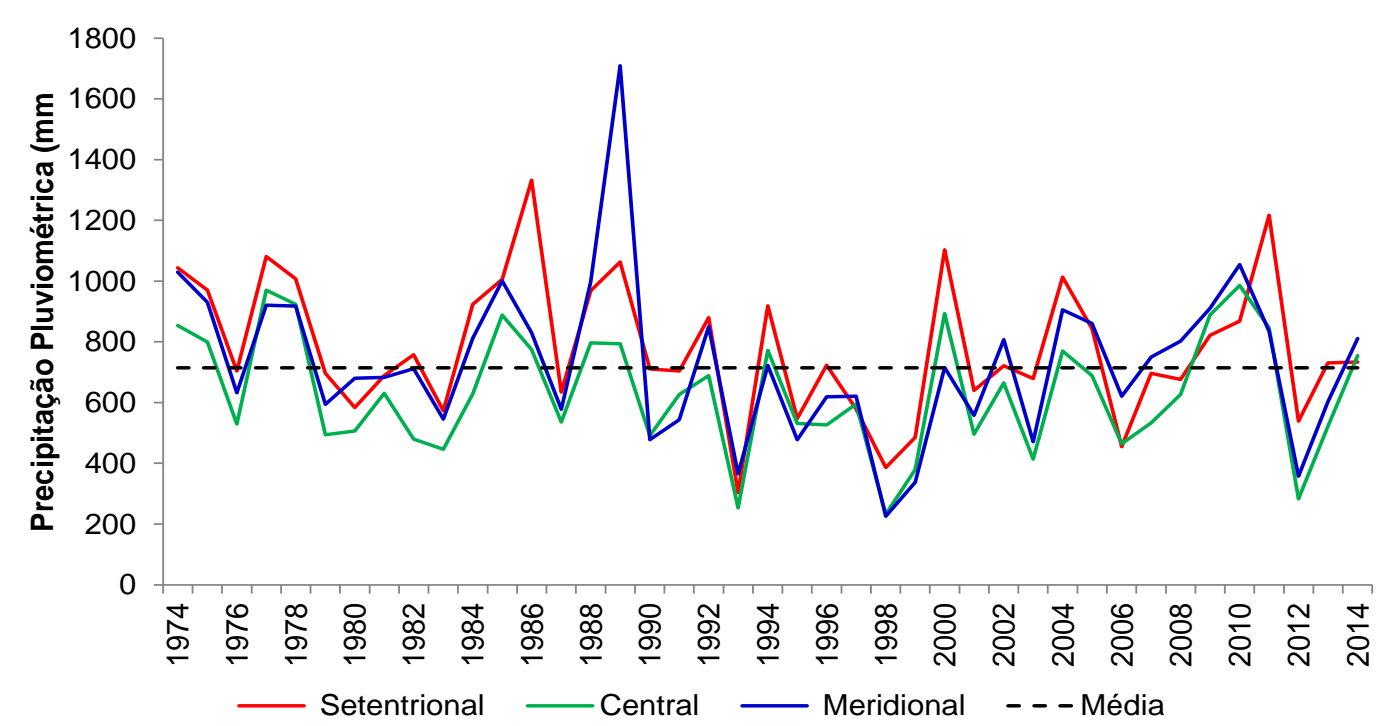

Figura 6 - Distribuição temporal da precipitação pluviométrica nas regiões do Agreste Setentrional, Central e Meridional e a média da região no período de 1974 a 2014.

Além da variabilidade climática que se expressa na não linearidade da precipitação ao longo dos anos, observa-se com mais nitidez a ocorrência de eventuais extremos climáticos. A Figura 6 exibe curvas semelhantes para as três regiões do Agreste de Pernambuco que revelam a existência de anos extremos chuvosos e secos no período estudado. Diante de tanta heterogeneidade, podem-se destacar os anos de 1978, 1986, 1989, 2000, 2005 e 2010 como anos atípicos em que o índice de precipitação foi muito superior à média da região, tendo seus indicadores mais altos no ano de 1986 no Agreste Setentrional, em torno de 1400 mm, e em 1989 no Agreste Meridional, ultrapassando os $1700 \mathrm{~mm}$.

A partir dos resultados expostos na Figura 6, conclui-se que também os anos secos se mostram de forma muito similar nas três microrregiões, não apresentando grandes divergências nesse sentido. $O$ comportamento da precipitação nos anos de 1993, 1998 e 2012, com os índices mais baixos registrados durante o período estudado, são praticamente iguais no Agrestes Meridional, Setentrional e Central, chegando a $300 \mathrm{~mm}$ anuais, o que representa um grave déficit hídrico em toda a região.

Efeitos diretos dos fenômenos climáticos extremos podem atuar sobre os processos sociais, culturais, demográficos, a qualidade da água e do ar ou a saúde humana. Como já pressuposto, a ocorrência de tais índices extremos podem acarretar expressivas alterações socioambientais na região, uma vez que o aporte tecnológico para lidar com essas adversidades é insuficiente. Dessa forma, o estudo da intensidade e constância das precipitações extremas na área de estudo é de grande interesse não só para a meteorologia, mas também de áreas afins. 


\section{INFLUÊNCIA DA VARIABILIDADE DA PRECIPITAÇÃO NA PRODUÇÃO DE LEITE}

A partir da Figura 7 é possível associar a evolução temporal da precipitação pluviométrica à produção de leite em toda a região Agreste, no período de 1974 a 2014. Nota-se que, embora não haja uma correspondência direta entre as duas variáveis, considerando de um lado a variabilidade do clima, e de outro toda a história do desenvolvimento de uma cadeia produtiva de leite com todos os seus elementos condicionantes, historicamente, o comportamento da precipitação correlaciona-se à produção de leite na ocorrência de eventos extremos climáticos, havendo respostas evidentes desta produção ao comportamento do regime pluviométrico, durante esses eventos.

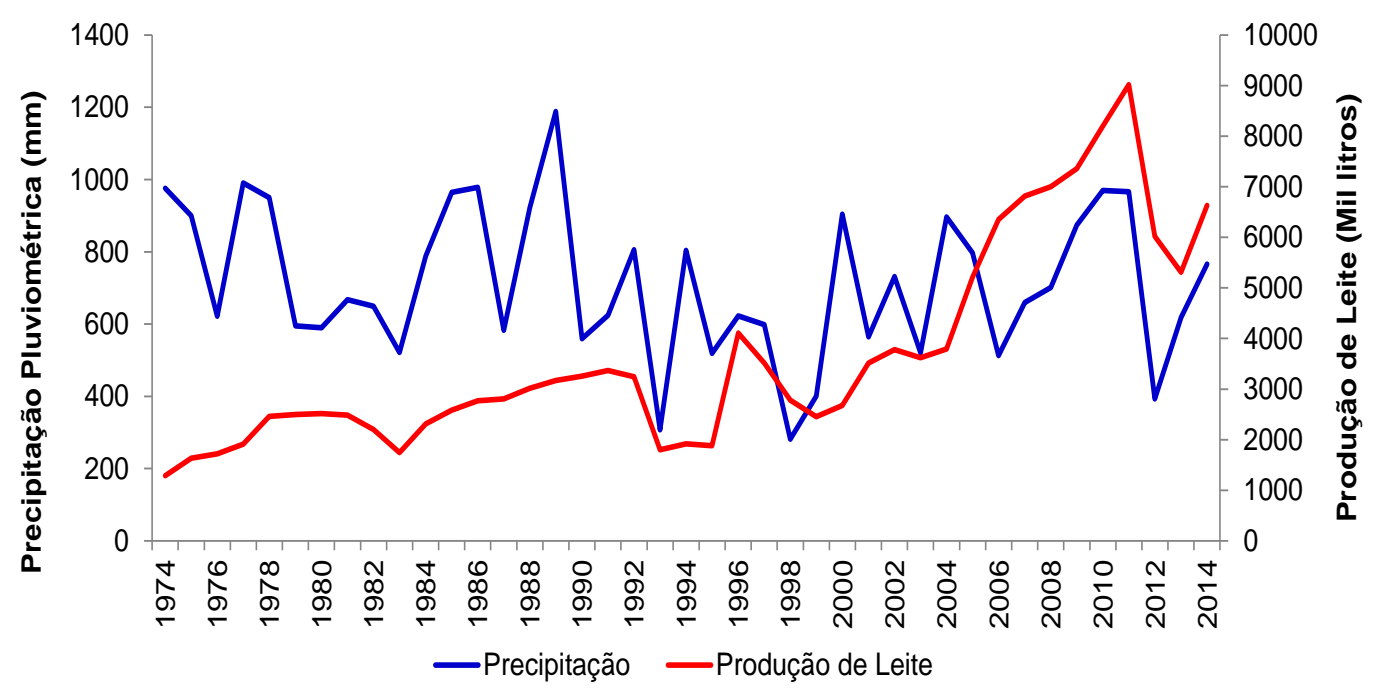

Figura 7 - Evolução temporal da precipitação pluviométrica e da produção de leite no período de 1974 a 2014 no Agreste pernambucano.

Observa-se no gráfico da Figura 7 que nos anos de 1983, 1993, 1998 e 2012 a produção de leite caiu, seguindo a curva da queda no regime de precipitação pluviométrica. Da mesma maneira, nota-se que de 2008 a 2011 as linhas de precipitação e produção exibem paralelamente 0 mesmo comportamento, aumentando a produtividade à medida que aumentam os índices de precipitação da região Agreste.

Uma investigação realizada por Santos et al. (2012) aponta para um fenômeno marcante na história das secas no Nordeste, uma estiagem que se estendeu do ano de 1979 até 1983 . Esse período, marcado pela ocorrência do El Niño 1982/1983, provocou intensas modificações no regime pluviométrico, causando uma estiagem considerada como uma das mais longas e severas da história do Nordeste, onde o número de mortos foi considerado como de uma calamidade pública. Tal fenômeno pode ser facilmente observado na Figura 7, onde os baixos índices pluviométricos são refletidos em toda a região Agreste, paralelamente a uma queda na produção de leite registrada no período. 
De forma geral, nos anos em que ocorrem situações de índices extremos climáticos, a resposta a essas condições expressa nas atividades humanas será mais evidente, uma vez que sua sensibilidade aos períodos de estiagem prolongada ou excesso de chuva é maior, pois embora se compreenda a variabilidade climática, não existe preparo suficiente para a ocorrência de eventos extremos.

Um fenômeno recente de grande expressividade nas duas variáveis expostas na Figura 7 demonstra a ocorrência de um acontecimento atípico no ano de 2012, uma queda significativa na produção de leite em razão do baixo índice de precipitação pluviométrica registrado neste ano. Essa ocorrência extrema foi comprovada a partir de variadas pesquisas científicas e retratada em várias passagens veiculadas na mídia impressa e digital.

Dados do ano de 2012 da Companhia Nacional de Abastecimento (CONAB) expõem que a forte estiagem registrada em toda a região semiárida acarretou danos expressivos na pecuária e na agricultura. As culturas de feijão e de milho apresentaram perdas superiores a $80 \%$. No estado da Paraíba, estimou-se perdas de $93,5 \%$ na produção de feijão e de $95,7 \%$ no milho. No Rio Grande do Norte, perda de $89,6 \%$ na produção de feijão e de $90,1 \%$ no milho, e no Ceará as perdas foram de $87,3 \%$ no feijão e $92,2 \%$, na cultura do milho.

Filho e Oliveira (2016), salientando que no Agreste pernambucano predomina utilização de sistemas de produção "sequeiro" (sem uso da irrigação) e a palma forrageira como fonte principal de alimento dos rebanhos, admitiram que a pluviosidade em 2012 foi muito inferior à média histórica, mostrando-se essa atividade extremamente vulnerável e evidenciando a necessidade em se realizar ajustes no modelo produtivo.

A partir das evidências encontradas na ocorrência de extremos climáticos, comprovadas através da análise do comportamento climático histórico na região Agreste de Pernambuco, correlaciona-se a produção de leite e a precipitação pluviométrica na área de estudo, salientando as condições climáticas extremas que anunciam essa relação. Tal dependência vem a afetar não apenas diretamente o rebanho no âmbito do conforto térmico, como a quantidade e qualidade do pasto, refletindo seus efeitos no setor industrial e na sobrevivência das famílias tradicionais de pequenos produtores.

\section{MODELO ESTATÍSTICO}

O modelo de regressão experimentou diversas equações na tentativa de correlacionar estatisticamente os dados de precipitação pluviométrica (variável independente) e produção de leite (variável dependente), de forma a materializar relações numéricas entre as variáveis. Para selecionar a melhor resposta, foram testados o modelo de regressão Linear, Logarítmico, Inverso, Quadrático, Cúbico, Potência, Composto, S, Logística, Crescimento e Exponencial, cujos resumos encontram-se reunidos na Tabela 2. 
Tabela 2 - Resultados dos modelos de regressão

\begin{tabular}{|l|c|c|c|c|}
\hline $\begin{array}{c}\text { Modelo de } \\
\text { regressão }\end{array}$ & R & R quadrado & $\begin{array}{c}\text { R quadrado } \\
\text { ajustado }\end{array}$ & $\begin{array}{c}\text { Erro padrão da } \\
\text { estimativa }\end{array}$ \\
\hline Linear & 0,194 & 0,038 & $-0,031$ & 540,302 \\
\hline Logarítmico & 0,173 & 0,03 & $-0,039$ & 542,512 \\
\hline Inverso & 0,158 & 0,025 & $-0,045$ & 543,893 \\
\hline Quadrático & $\mathbf{0 , 3 3 3}$ & 0,111 & $-0,026$ & 538,886 \\
\hline Cúbico & $\mathbf{0 , 3 6 5}$ & 0,133 & 0 & 532,157 \\
\hline Composto & 0,128 & 0,016 & $-0,054$ & 0,256 \\
\hline Potência & 0,111 & 0,012 & $-0,058$ & 0,257 \\
\hline$\underline{S}$ & 0,1 & 0,01 & $-0,061$ & 0,257 \\
\hline Crescimento & 0,128 & 0,016 & $-0,054$ & 0,256 \\
\hline Exponencial & 0,128 & 0,016 & $-0,054$ & 0,256 \\
\hline Logística & 0,128 & 0,016 & $-0,054$ & 0,256 \\
\hline
\end{tabular}

A avaliação dos modelos estatísticos resultou na identificação de duas respostas expressivas para correlacionar a produção de leite ao comportamento da precipitação pluviométrica na área de estudo. Conforme pode ser observado na Figura 9, os modelos são o quadrático (33\%) e o cúbico (36\%), que apresentam uma curva acentuada, diferenciando-se dos demais modelos experimentados. Estes resultados indicam que a variável precipitação contribui com 36\% (cúbico) e 33\% (quadrático) na produção de leite anual no Agreste pernambucano, implicando na consolidação de ferramentas que podem subsidiar análises científicas e constituir estudos direcionados à adaptação da atividade ao comportamento climático em vários âmbitos. 


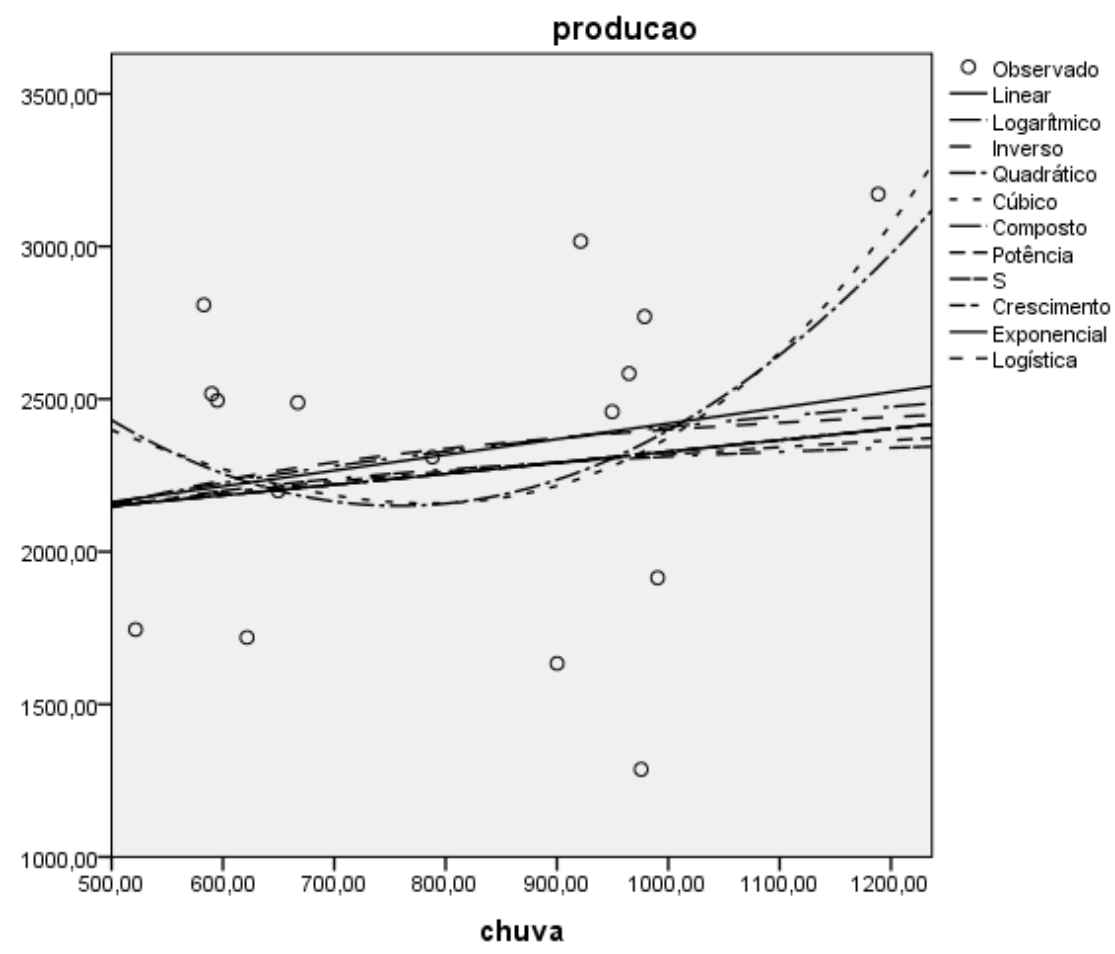

Figura 8 - Resposta dos modelos de correlação às variáveis produção de leite e precipitação pluviométrica

\section{CONSIDERAÇÕES FINAIS}

$\mathrm{Na}$ análise das tendências climáticas da precipitação pluviométrica através do Climap 3.0, as médias mensais e trimestrais da precipitação indicaram grande irregularidade na distribuição do período chuvoso ao longo do ano, concentrando sua ocorrência no final do primeiro e no segundo trimestres. Os totais anuais da precipitação e o desvio padronizado, por sua vez, comprovaram a alta variabilidade anual do clima, mas a qualidade dos dados foi insatisfatória na geração do gráfico de desvio padronizado para gerar resultados concisos acerca das tendências de precipitação, que não expuseram tendências significativas. Por outro lado, os índices extremos de precipitação demonstraram, em sua quase totalidade, tendências negativas para as três microrregiões do Agreste pernambucano, apontando a diminuição da ocorrência destes índices, com a exceção do extremo sul do Agreste Setentrional, que aponta tendências positivas para Pr1.

A partir da análise dos impactos da variabilidade climática na produção de leite em escala temporal, evidenciou-se que a distribuição temporal da produção de leite na região de estudo atribui ao Agreste Meridional a maior contribuição na produção, sendo sua produtividade muito acima da média da região. Quanto à distribuição temporal da precipitação pluviométrica, em contrapartida, se expressa de forma muito semelhante nas três microrregiões, mas os Agrestes Setentrional e Meridional apresentam índices um pouco mais elevados. Há de se considerar ainda que, na ocorrência de extremos climáticos, os índices de precipitação das três microrregiões apresentam o mesmo comportamento. O modelo de regressão identificou respostas diretas do 
comportamento da produção à precipitação, especialmente na ocorrência de em eventos extremos climáticos.

A experimentação do modelo estatístico obteve resultados significativos para os modelos cúbico e quadrático, que apresentaram os melhores resultados, indicando que a precipitação contribui com 36\% (Cúbico) e 33\% (Quadráticos) com a produção de leite na região. É importante ressaltar que outras variáveis, como as temperaturas máxima e mínima, umidade relativa do ar e disponibilidade hídrica também devem apresentar um percentual de contribuição na produção leiteira.

Para aperfeiçoar os resultados de pesquisas dessa natureza, sugere-se inicialmente o investimento no registro de dados climatológicos em longo prazo em quantidade e qualidade, a fim de subsidiar análises posteriores, onde se forneçam dados precisos para gerar análises cada vez mais fidedignas e através dos quais seja possível um nível de detalhamento apropriado para cada realidade local, considerando todas as suas especificidades.

Como proposição para a utilização dos dados aqui identificados, recomenda-se que no planejamento público estejam previstos o incentivo de longo prazo à adoção de tecnologias apropriadas como instrumento de desenvolvimento local, considerando as especificidades da região Agreste para adaptação às adversidades climáticas do ambiente semiárido; a inserção dos pequenos produtores nos espaços de diálogo e tomada de decisão para fortalecimento da produção de agricultura familiar; a busca por formas de produção menos impactantes ao ambiente; possibilidades de garantir o acesso das propriedades rurais às espécies de palma forrageira mais adequadas às condições de cada local em que se encontram, bem como oportunizá-las o dimensionamento proporcional desse suporte ao tamanho do rebanho e a garantia de tecnologias para formas de armazenamento de água em quantidade e qualidade suficientes para suas necessidades de produção.

\section{AGRADECIMENTOS}

À Fundação de Amparo à Ciência e Tecnologia de Pernambuco (FACEPE) por meio do Projeto de Pesquisa APQ-0762-1.07/15; ao Ministério da Ciência, Tecnologia e Inovação (MCTI), por intermédio do Conselho Nacional de Desenvolvimento Científico e Tecnológico (CNPq), e a Agência Nacional de Águas (ANA), por meio do edital MCTI/CNPq/ANA n.23/2015.

\section{REFERÊNCIAS}

ASSIS, J. M. O.; SOUZA, W. M.; SOBRAL, M. C. M. Climate analysis of the rainfall in the lower-middle stretch of the São Francisco river basin based on the rain anomaly index. Revista Brasileira de Ciências Ambientais, v. 2, p. 188-202, 2015.

CONDEPE/FIDEM. Plano de Desenvolvimento Sustentável Área de Influência do Município de Bom Conselho. AGR gráfica e Editora Ltda. Recife, 2016.

CORREIA, E. Bloqueios e possibilidades para o surgimento de espaços inovativos periféricos: o caso do setor leiteiro na região de Garanhuns/ Pernambuco. Tese 
de Doutorado - Universidade Federal de Pernambuco, CFCH. Programa de Pós Graduação em Geografia, 2012.

EMBRAPA - Empresa Brasileira de Pesquisa Agropecuária. Semiárido Brasileiro: Pesquisa, Desenvolvimento e Inovação. Petrolina: Embrapa Semiárido, 2010.

EMBRAPA - Empresa Brasileira de Pesquisa Agropecuária. Competitividade da cadeia produtiva do leite em Pernambuco. Juiz de Fora, Embrapa, 2009, 376p.

FILHO, R.J.C.R., OLIVEIRA, F.Z. Opções de produção de alimento para pecuária de Pernambuco - uso das aeras irrigadas. SEBRAE (2016).

GALVÍNCIO, J. D.; MOURA, M.S.B. Aspectos climáticos da captação de água de chuva no Estado de Pernambuco. Revista de Geografia, Recife, vol.22, N02, 2005.

LIMA, M. C. G.; SÁ, S. M. F.; SOUZA, W. M.; SANTOS, T. E. M. Impactos gerados e a gestão da bacia do rio Capibaribe-PE. Journal of Environmental Analysis and Progress, v.03, p.75-85, 2018.

MEDEIROS, B.C., BARRETO, A.B., OLIVEIRA, J.D.A., ARAGÃO, M.R.S. Análise quantitativa da variabilidade da chuva em João Pessoa - PB, em várias escalas de tempo. Revista Brasileira de Geografia Física. v8 (2015), 1748-1761.

MONTEIRO, A.A., TAMANINI, R., SILVA, L.C.C., MATTOS, M.R., MAGNANI, D.F., OVIDIO, D., NERO, L.A., BARROS, M.A.F., PIRES, E.M.F., PAQUEREAU, B.P.D., BELOTI, V. Características da produção leiteira da região Agreste do Estado de Pernambuco, Brasil. Semina: Ciências Agrárias. Londrina, v.8, n4, p. 665-674, out/dez. 2007.

PEREIRA, M. L. T.; SOARESA, M. P. A., SilvA, E. A.; MONTENEGRO, A. A. A.; SOUZA, W. M. Variabilidade climática no Agreste de Pernambuco e os desastres decorrentes dos extremos climáticos. Journal of Environmental Analysis and Progress, v. 02, p. 394-402, 2017.

PEZZOPANE, J.E.M, NETO, S.N.O., VILELA, M.F. Risco de incêndios em função da característica do clima, relevo e cobertura do solo. Floresta e Ambiente. V8, n1, p. 161-166, 2011.

PIRES, M. F. A.; TEODORO, R. L.; CAMPOS, A. T. Efeito do estresse térmico sobre a produção de bovinos. In: Congresso Nordestino de Produção de Ruminantes. Ruminantes e Não Ruminantes, 2., 2000, Teresina. Anais. Teresina: Sociedade Nordestina de Produção Animal, 2000. p.87- 105.

SALVADOR, M. A. Análise da variabilidade climática na nova fronteira agrícola do Brasil: região do MATOPIBA. Tese de Doutorado. Universidade Federal de Campina Grande, Centro de Tecnologia e Recursos Naturais. 101p. Campina Grande-PB, 2014.

SALVADOR, M. A. CLIMAP - APLICATIVO PARA ANÁLISE DE DADOS CLIMÁTICOS-VERSÃO 3.0. Revista Brasileira de Climatologia. Ano 13 - Vol. 20 JAN/JUL 2017.

SANTOS, C.A.C., MELO, M.S., BRITO, J.I.B. Tendências de índices extremos climáticos para o Estado do Amazonas e suas relações com a TSM dos oceanos tropicais. Revista Brasileira de Meteorologia. v.31, n.1, 1-10, 2016. 
SANTOS, E., mAtos, H., AlvarengA, J., SAles. M.C.L. A seca no Nordeste no ano de 2012: relatório sobre a estiagem na região e o exemplo de prática de convivência com o Semiárido no distrito de Iguaçu/Canindé-CE. Revista Geonorte, Ed. Especial 2, v1, n.5, p. 819-930, 2012.

SEBRAE. Cenários para o Leite e Derivados na Região Nordeste em 2020. Recife: SEBRAE, 2013. 